\title{
Binocular Integration of Perceptually Suppressed Visual Information in Amblyopia
}

\author{
Amy Chow, ${ }^{1}$ Andrew E. Silva, ${ }^{1}$ Katelyn Tsang, ${ }^{1}$ Gabriel $\mathrm{Ng}^{2}$ Cindy $\mathrm{Ho}^{2}{ }^{2}$ and \\ Benjamin Thompson ${ }^{1,3,4}$ \\ ${ }^{1}$ Department of Optometry and Vision Science, University of Waterloo, Waterloo, Ontario, Canada \\ ${ }^{2}$ Mount Pleasant Optometry Centre, Vancouver, British Columbia, Canada \\ ${ }^{3}$ Center for Eye and Vision Research, 17W Science Park, Hong Kong \\ ${ }^{4}$ Liggins Institute, University of Auckland, Auckland, New Zealand
}

Correspondence: Amy Chow, Department of Optometry and Vision Science, University of Waterloo, 200 University Avenue, Waterloo, Ontario N2L 3G1, Canada; amy.chow@uwaterloo.ca.

Received: January 18, 2021

Accepted: August 20, 2021

Published: September 13, 2021

Citation: Chow A, Silva AE, Tsang K, Ng G, Ho C, Thompson B. Binocular integration of perceptually suppressed visual information in amblyopia. Invest Ophthalmol Vis Sci. 2021;62(12):11.

https://doi.org/10.1167/iovs.62.12.11
Purpose. The purpose of this study was to assess whether motion information from suppressed amblyopic eyes can influence visual perception.

Methods. Participants with normal vision $(n=20)$ and with amblyopia $(n=20 ; 11$ anisometropic and 9 strabismic/mixed) viewed dichoptic, orthogonal drifting gratings through a mirror stereoscope. Participants continuously reported form and motion percepts as gratings rivaled for 60 seconds. Responses were binned into categories ranging from binocular integration to complete suppression. Periods when the grating presented to the nondominant/amblyopic eye was suppressed were analyzed further to determine the extent of binocular integration of motion.

REsults. Individuals with amblyopia experienced longer periods of non-preferred eye suppression than controls. When the non-preferred eye grating was suppressed, binocular integration of motion occurred $48.1 \pm 6.2 \%$ and $31.2 \pm 5.8 \%$ of the time in control and amblyopic participants, respectively. Periods of motion integration from the suppressed eye were significantly non-zero for both groups.

Conclusions. Visual information seen only by a suppressed amblyopic eye can be binocularly integrated and influence the overall visual percept. These findings reveal that visual information subjected to interocular suppression can still contribute to binocular vision and suggest the use of appropriate optical correction for the amblyopic eye to improve image quality for binocular combination.

Keywords: suppression, amblyopia, motion perception, binocular rivalry, binocular vision

\begin{abstract}
A bnormal visual experience in early childhood, typically caused by the misalignment of one eye (strabismus) or a large difference in focusing power between the eyes (anisometropia), can alter the course of normal visual development resulting in a disorder called amblyopia. Amblyopia causes reduced visual acuity when viewing with the affected eye, monocular losses, such as poor contrast sensitivity and positional acuity, as well as binocular losses, including impaired stereoacuity. ${ }^{1-6}$ A key component of amblyopia is the presence of strong, chronic suppression of the amblyopic eye. Early clinical studies identified a distinct blind spot (termed a scotoma) within the amblyopic visual field when both eyes were open. ${ }^{7-9}$ There was no conscious awareness of stimuli presented within the suppression scotoma, suggesting that the scotoma was absolute (similar to the blind spot created by the optic nerve). Instead, overall visual perception was dominated by what was seen by the nonamblyopic fellow eye. Since then, quantitative techniques have been developed to measure the extent and severity of suppression scotomas. ${ }^{10-13}$ Although there is marked suppression across the entire amblyopic eye visual field, ${ }^{13}$ suppression is strongest within the foveal region. ${ }^{12}$ Within
\end{abstract}

the central region of a suppression scotoma, luminance ${ }^{14}$ and increment ${ }^{15,16}$ thresholds are significantly elevated and contrast sensitivity is reduced to $10 \%$ to $30 \%{ }^{12,13}$ of the stimulus strength, resulting in a significant weakening of the amblyopic eye signal. Suppression appears similar in strength between the anisometropic and strabismic forms of amblyopia, ${ }^{12,13,17,18}$ and suppression strength is positively correlated with the severity of amblyopia. ${ }^{17-20}$ Although interocular suppression resolves conflicting visual input from each eye to avoid diplopia and visual confusion, it acts as a significant barrier to the recovery of binocular vision in the treatment of amblyopia.

Due to the weakened amblyopic eye signal, the suppressed amblyopic eye contributes little if anything to the binocular experience, because the fellow eye signal dominates conscious visual perception. ${ }^{21-24}$ Suppression of the amblyopic eye has been thought to preclude its contribution to binocular processing and conscious visual perception. ${ }^{25-28}$ For instance, the lack of stereopsis in amblyopia is largely due to suppression and subsequent abnormal binocular processing rather than the monocular loss of resolution and sensitivity. ${ }^{29,30}$ This is in part due to 
the asymmetrical suppressive influence between the eyes in favor of the fellow eye..$^{21,31-34}$ These suppressive interactions are contrast- and spatial frequency-dependent, with stronger suppression being generated by high contrast and high spatial frequencies. ${ }^{24,32,34,35}$ Suppression can be alleviated by presenting higher contrast stimuli to the amblyopic eye than the fellow eye. ${ }^{21-23,34,36,37}$ At a particular, personal, interocular contrast ratio (known as the balance point), the asymmetrical suppressive interactions favoring the fellow eye can be neutralized, enabling simultaneous visual perception ${ }^{10,21}$ as well as binocular combination. ${ }^{21-23,34,36,37}$ Although these findings demonstrate that the binocular architecture within the amblyopic brain is structurally intact, the amblyopic visual system is still considered to be functionally monocular due to interocular suppression during normal binocular viewing.

Within the normal visual system, interocular suppression can be simulated by artificially presenting conflicting images to each eye, eliciting a phenomenon known as binocular rivalry. ${ }^{38}$ During binocular rivalry, conscious visual perception is dominated by one eye while the other eye is suppressed. Suppression and dominance alternate between the eyes periodically. During periods of monocular dominance, the suppressed eye suffers from a substantial reduction in sensitivity, ${ }^{39-43}$ reminiscent of amblyopic eye suppression. In individuals with normal binocular vision, suppressed visual information remains available for cortical processing and can influence perception. For instance, form information from the orientation of a rivalry-suppressed grating can systematically bias the perceived orientation of a grating shown to the dominant eye. ${ }^{44}$ Similarly, the perception of apparent motion ${ }^{45}$ and the motion after-effect ${ }^{46-48}$ persist despite being presented only to the rivalry-suppressed eye. Stereoscopic information can be combined for judgments of depth despite rivalry suppression. ${ }^{49}$ Furthermore, neuroimaging studies have shown that information from a suppressed eye retains a presence within the brain. ${ }^{50-52}$ These results indicate that suppressed visual information remains available for cortical processing.

Experiments using plaid stimuli have generated critical insights into motion integration within striate and extrastriate visual cortex. Comprised of two gratings with different orientations and motion directions drifting within a circular aperture, plaid stimuli can be perceived as two individual gratings moving in their respective directions (referred to as component motion) or a plaid pattern moving coherently in a single direction that is distinct from the two component directions (referred to as pattern motion). ${ }^{53}$ These two percepts alternate for dominance when plaid stimuli are viewed for an extended period of time..$^{54-56}$ Plaid stimuli have been used to investigate how the brain solves the aperture problem; the fact that motion direction signals are ambiguous when seen through an aperture, such as an individual receptive field in V1. In particular, the motion direction of an edge appears to be perpendicular to its orientation when viewed through an aperture, regardless of its actual motion direction. ${ }^{57}$ Therefore, to identify the veridical motion direction of an edge or moving object, the visual system must integrate motion information across multiple adjacent receptive fields. ${ }^{57}$ Hierarchical two-stage models have proposed that local, component motion signals (susceptible to the aperture problem) are extracted within the primary visual cortex (V1). Component motion signals are then integrated in the extrastriate middle temporal (MT) cortex to compute the veridical motion direction. ${ }^{53,57-66}$ Indeed, neurophysiological studies using plaid stimuli found that nearly all V1 cells responded to the direction of the individual grating components with none responding to the pattern direction. ${ }^{60,62,67,68}$ On the other hand, a subset of MT neurons displayed responses that matched the pattern motion direction indicating integration of the local component motion directions. ${ }^{60,65,69}$ Although a small number of pattern-selective cells do exist in $\mathrm{V} 1,^{70,71}$ it appears that pattern cells in MT use the outputs of V1 cells to compute motion over a larger spatial extent than $\mathrm{V}^{72}$ (although see Ref. 73). Computation of the overall pattern direction is determined by a geometric solution using the intersection of constraints or vector averaging ${ }^{74-76}$ and has been the subject of extensive modeling. ${ }^{66,75,77}$ Consistent with this hierarchical model, application of repetitive transcranial magnetic stimulation (rTMS) to reduce cortical excitability over the striate cortex in humans increased pattern motion percepts, whereas rTMS over extrastriate V5 (the human analogue of MT) cortex reduced pattern motion percepts. ${ }^{78}$ This result reveals the critical role of $\mathrm{V} 5$, such that disruption of function reduces pattern motion computation and biases perception in favor of component motion percepts. ${ }^{78}$

Plaid perception is normal in amblyopia..$^{56,79}$ However, neuroimaging has revealed that plaid perception may be supported by different neural networks in individuals with amblyopia than individuals with normal vision. Specifically, the perception of pattern motion in plaid stimuli was correlated with V5 activity in controls and pulvinar and V3 activity in the amblyopia group, suggesting the existence of compensatory mechanisms for motion processing. ${ }^{80}$ The perception of pattern motion depends on the spatial and temporal properties of the two component gratings. Pattern motion is more likely to be perceived for component gratings with similar contrast, ${ }^{81-85}$ spatial frequency, ${ }^{56,81,82,86}$ and speed. ${ }^{53,81,82}$ If the gratings are unbalanced, perception is biased toward the component grating with higher contrast ${ }^{84}$ higher spatial frequency, ${ }^{56,81,82,86}$ or faster speed. ${ }^{53,81,82}$ When plaid stimuli are presented dichoptically (one component grating to each eye), form rivalry can occur whereby the spatial properties of only one component grating are perceived. However, form rivalry does not prevent the binocular combination of motion information when viewing dichoptic plaids. ${ }^{81,87-90}$ Specifically, observers may perceive a single component grating (form suppression) moving in the pattern motion direction, suggesting binocular integration of motion. If motion information from a suppressed eye can be integrated binocularly in the normal visual system, it remains an open question whether this phenomenon can occur in amblyopia. How inputs from the suppressed amblyopic eye are handled by the brain remains unknown.

In this study, we explored whether visual information from a suppressed amblyopic eye can influence the conscious perception of stimuli presented to the fellow eye. Using $100 \%$ contrast dichoptic gratings to maximally engage suppression of the amblyopic eye, we explored whether binocular integration of motion can occur during periods of amblyopic eye form suppression in binocular rivalry. Based on previous work in individuals with normal vision, ${ }^{81,87-90}$ we reasoned that if binocular combination can occur despite suppression of the amblyopic eye, motion presented to the suppressed amblyopic eye would influence the motion direction perceived by the fellow eye. Such a result would demonstrate that despite strong amblyopic eye suppression, amblyopic eye information can still contribute to binocular vision. 


\section{Materials AND Methods}

\section{Observers}

Participants with normal vision $(n=20$, mean \pm SE 23.9 \pm 0.7 years, 16 women) and amblyopia ( $n=20,39.5 \pm$ 3.1 years, 9 women) took part in this study. All participants were naïve to the experimental hypothesis and were reimbursed for their time. Participants provided written informed consent to take part in the study, and the study protocol was approved by the institutional ethics committee at the University of Waterloo, in accordance with the Declaration of Helsinki. Participants were screened at the School of Optometry and Vision Science at the University of Waterloo, Waterloo, Ontario, Canada or at the Mount Pleasant Optometry Centre, Vancouver, British Columbia, Canada. Clinical assessment included visual acuity (electronic Early Treatment Diabetic Retinopathy Study [ETDRS] chart), eye alignment (distance and near cover test) and stereoacuity (Randot Preschool Stereotest; Stereo Optical Co. Inc., Chicago, IL, USA). Amblyopia was defined as a minimum of a two logMAR line difference in visual acuity between the eyes associated with either anisometropia ( $>1$ diopter difference in spherical equivalent between the eyes or $>1.5$ diopters of cylinder in one eye) and/or strabismus (including history of strabismus surgery), with otherwise normal ocular and general health. All participants had a $0.2 \log$ MAR interocular visual acuity difference except for participant A07, who had undergone successful treatment of amblyopia with previous patching. All participants wore their habitual correction as needed. In participants with normal vision, the preferred eye was determined as the eye more sensitive to blur when a +2.00 DS lens was held over one eye while binocularly observing letters 0.2 logMAR above their best-corrected visual acuity (a measure of sensory dominance). The preferred eye in participants with amblyopia was defined as the eye with better bestcorrected visual acuity. Henceforth, the term nonpreferred eye will be used to refer to amblyopic eyes in the amblyopia group and nondominant eyes in the normal vision group. Clinical details for individuals with amblyopia (11 anisometropic and 9 strabismic/mixed) are summarized in the Table. Data and analysis codes are available online from the University of Waterloo's repository.

\section{Experimental Design}

Participants viewed drifting dichoptic orthogonal gratings ( 1 cpd, 4 degrees diameter, 100\% contrast, and moving at 0.25 cycles/s) through a mirror stereoscope (Fig. 1). The optical path length from the stereoscope to the display was $67 \mathrm{~cm}$. Stimuli were presented on an Acer 27" LED monitor (HA270) at a resolution of $1920 \times 1080$ and 75 hertz $(\mathrm{Hz})$. Mean luminance of the grating and uniform grey background was $15.6 \mathrm{~cd} / \mathrm{m}^{2}$ and $14.5 \mathrm{~cd} / \mathrm{m}^{2}$, respectively. Each trial lasted 60 seconds and participants performed 42 trials in total. Initial alignment was performed using a Nonius cross ( 2.5 degrees in width and height) and the participants maintained fixation on a smaller Nonius cross ( 0.63 degrees in width and height) during rivalry periods. A binocular fusion square subtending 8.95 degrees (width and height) was present at all times. Through the stereoscope, the preferred eye always viewed a grating oriented 45 degrees moving up and to the left (motion direction 135 degrees), and the nonpreferred eye always viewed a grating oriented 135 degrees moving up and to the right (motion direction 45 degrees). As the gratings underwent binocular rivalry, participants continuously reported their form percept using three keys (single grating oriented

TABLe. Clinical Details for Participants With Amblyopia

\begin{tabular}{|c|c|c|c|c|c|c|c|}
\hline ID & Age/Gender & Type & VA (FE) & VA (AE) & Stereoacuity & $\begin{array}{l}\text { Ocular Deviation } \\
\quad \text { (Near) }\end{array}$ & Clinical History \\
\hline A01 & $25 / \mathrm{F}$ & A & $20 / 20$ & $20 / 100$ & $>800 "$ & $\mathrm{NS}, 12 \Delta \mathrm{XP}$ & Unknown history \\
\hline A02 & $24 / \mathrm{F}$ & A & $20 / 20$ & $20 / 40$ & $>400 "$ & NS, ortho & Dx at 3-4 y, patched $2-3 \mathrm{~h} /$ day until $8 \mathrm{y}$ \\
\hline A03 & 29/M & A & $20 / 20$ & $20 / 50$ & $>800 "$ & NS, ortho & Dx since childhood, no patching or surgery \\
\hline A04 & $66 / \mathrm{F}$ & A & $20 / 25$ & $20 / 200$ & $>800 "$ & NS, ortho & Dx at $10 \mathrm{y}$, patched all day \\
\hline A05 & $44 / \mathrm{M}$ & M & $20 / 20$ & $20 / 60$ & $>800 "$ & $4 \Delta$ RET & $\begin{array}{l}\text { Dx and surgery for ET at } 4 \mathrm{y} \text {, patched } 8 \mathrm{~h} / \text { day at } 5 \mathrm{y} \text {, had } \\
\text { VT }\end{array}$ \\
\hline A06 & $42 / \mathrm{M}$ & M & $20 / 15$ & $20 / 80$ & $>800 "$ & $4 \Delta \mathrm{LXT}$ & $\begin{array}{l}\text { Dx } 4-5 \mathrm{y} \text {, FT glasses at } 13 \mathrm{y} \text {, eye surgery at } 31 \mathrm{y} \text { for XT, } \\
\text { patched } 1 \mathrm{~h} / \text { day }\end{array}$ \\
\hline A07 & $21 / \mathrm{F}$ & A & $20 / 20$ & $20 / 25$ & $60 "$ & NS, ortho & Patched at $2-3$ y \\
\hline A08 & 28/M & A & $20 / 15$ & $20 / 200$ & $>800 "$ & $\mathrm{NS}, 2 \Delta \mathrm{XP}$ & Dx 5-6 y, patched all day \\
\hline A09 & 28/M & $\mathrm{s}$ & $20 / 15$ & $20 / 25$ & $>800 "$ & $17 \Delta \mathrm{LXT}$ & Dx 3-4 y, glasses, surgery for XT at 7-8 y, had VT \\
\hline A10 & $45 / \mathrm{M}$ & A & $20 / 15$ & $20 / 50$ & $>800 "$ & NS, ortho & Dx at $4-5 \mathrm{y}$, patched until $6 \mathrm{y}$, had VT \\
\hline A11 & $40 / \mathrm{F}$ & $\mathrm{s}$ & $20 / 15$ & $20 / 30$ & $>800 "$ & $8 \Delta$ RET & Unknown history \\
\hline A12 & 24/M & A & $20 / 15$ & $20 / 30$ & $60 "$ & NS, ortho & Dx at $16 \mathrm{y}$, glasses, had VT \\
\hline A001 & $46 / \mathrm{F}$ & M & $20 / 20$ & $20 / 40$ & $>800 "$ & $12 \Delta \mathrm{RXT}$ & Glasses and patching during childhood, had VT \\
\hline A002 & $57 / \mathrm{F}$ & M & $20 / 20$ & $20 / 70$ & $>800^{\prime \prime}$ & $16 \Delta \mathrm{RXT}$ & $\begin{array}{l}\text { ET in childhood, had surgery for ET, was non-compliant } \\
\text { with patching, had VT }\end{array}$ \\
\hline A004 & 36/M & M & $20 / 20$ & $20 / 40$ & $>800 "$ & $10 \Delta$ LET & Dx at 1-2 y, had surgery, patched until $9 \mathrm{y}$, had VT \\
\hline A005 & 39/M & $\mathrm{s}$ & $20 / 20$ & $20 / 60$ & $>800 "$ & $8-10 \Delta$ RET & PT glasses \\
\hline A006 & 61/M & A & $20 / 20$ & $20 / 70$ & $>800 "$ & NS, ortho & Dx at $5 \mathrm{y}$, was non-compliant with patching \\
\hline A007 & $60 / \mathrm{M}$ & A & $20 / 20$ & $20 / 30$ & $>800 "$ & NS, $6 \Delta \mathrm{XP}$ & Dx in adulthood \\
\hline A009 & $28 / \mathrm{F}$ & A & $20 / 20$ & $20 / 30$ & $100 "$ & NS, 8-10 $\Delta \mathrm{XP}$ & Patching from $2-7 \mathrm{y}$ \\
\hline A010 & $46 / \mathrm{F}$ & M & $20 / 25$ & $20 / 60$ & $>800$ & $\begin{array}{c}\text { Constant alternating } \\
10 \Delta \text { ET }\end{array}$ & Patching from $5-8 \mathrm{y}$ \\
\hline
\end{tabular}

Some identifier codes are omitted as some participants could not fuse in the stereoscope. Participants with ID A\#\# were tested in Waterloo and ID A\#\#\# were in Vancouver.

$\mathrm{M}=$ male; $\mathrm{F}=$ female; $\mathrm{VA}=$ visual acuity; $\mathrm{A}=$ anisometropia; $\mathrm{S}=$ strabismus; $\mathrm{M}=$ mixed (anisometropia and strabismus) $\mathrm{NS}=$ nonstrabismic; $\mathrm{XP}=$ exophoria; $\mathrm{RET}=$ right esotropia; $\Delta=$ prism diopters; $\mathrm{Dx}=$ diagnosed $; \mathrm{FT}=$ full-time; $\mathrm{PT}=$ part-time; $\mathrm{VT}=$ vision therapy (orthoptics and/or dichoptic binocular amblyopia treatment). 

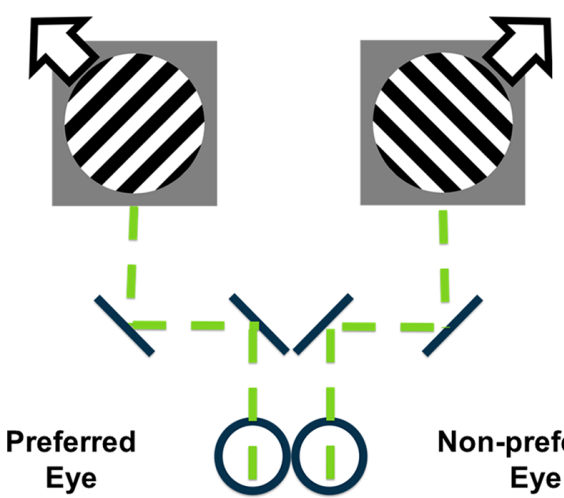

Non-preferred Eye

Figure 1. Plaid stimuli comprised of two high-contrast orthogonal drifting gratings were presented dichoptically using a mirror stereoscope. The dominant eye always viewed a grating oriented 45 degrees moving up and to the left, and the nonpreferred eye always viewed a grating oriented 135 degrees moving up and to the right. Arrows indicate the direction of motion.

45 degrees, single grating oriented 135 degrees, or any piecemeal combination). Participants were instructed that any mixture or superimposition of the two gratings, even partially, should be considered as piecemeal. Motion direction percepts were reported by using a mouse to control an on-screen arrow. Due to inherent response variability, mouse responses were binned to the nearest 45 degrees, 90 degrees, or 135 degrees motion direction (i.e. any mouse responses with a polar angle between 113 and 158 degree were counted as a motion direction of 135 degrees). This small range of angles around each expected direction of motion took into consideration the need for participants to provide form and motion direction responses concurrently. Transparent motion (i.e. the percept of two separate motion directions, one for each grating) was reported by pressing the piecemeal key without a concurrent mouse button press. Participants were given an unlimited practice period to master the controls prior to starting the test trials. To đ ensure participants were responding accurately, six catch trials with monocularly presented stimuli were randomly interleaved within trial blocks.

Responses were binned into one of the following response categories (see Fig. 2 for schematics of the associated percepts):

1. Full binocular integration of form and motion information.

2. Transparent motion.

3. Preferred eye form suppression with concurrent binocular integration of motion.

4. Preferred eye motion suppression with simultaneous binocular form perception.

5. Nonpreferred eye form suppression with concurrent binocular integration of motion.

6. Nonpreferred eye motion suppression with simultaneous binocular form perception.

7. Full suppression of the nonpreferred eye.

8. Full suppression of the preferred eye.

To examine the extent of motion integration while the nonpreferred eye was suppressed (Fig. 3), data were considered from participants who reported nonpreferred eye suppression for at least 2 minutes ( $5 \%$ of total viewing time). During periods of nonpreferred eye form suppression, corresponding motion information from the nonpreferred eye was determined to be either integrated (category 5) or suppressed (category 7; see Fig. 3 for a schematic). Figure 3 shows the extent of motion integration respectively between the two groups, computed as the ratio (category 5/category $5+7$ ) for motion integration. ${ }^{87}$

\section{Statistical Analysis}

Comparisons between the normal vision and amblyopia groups were made using an independent samples $t$-test, and comparisons within each group were made using paired samples $t$-tests. Periods of partial integration (categories 36) were analyzed with a 2 (eye: preferred eye and nonpreferred eye) $\times 2$ (suppression: form and motion) $\times 2$ (group: normal and amblyopia) repeated measures ANOVA. Post hoc analyses were conducted on significant interactions using

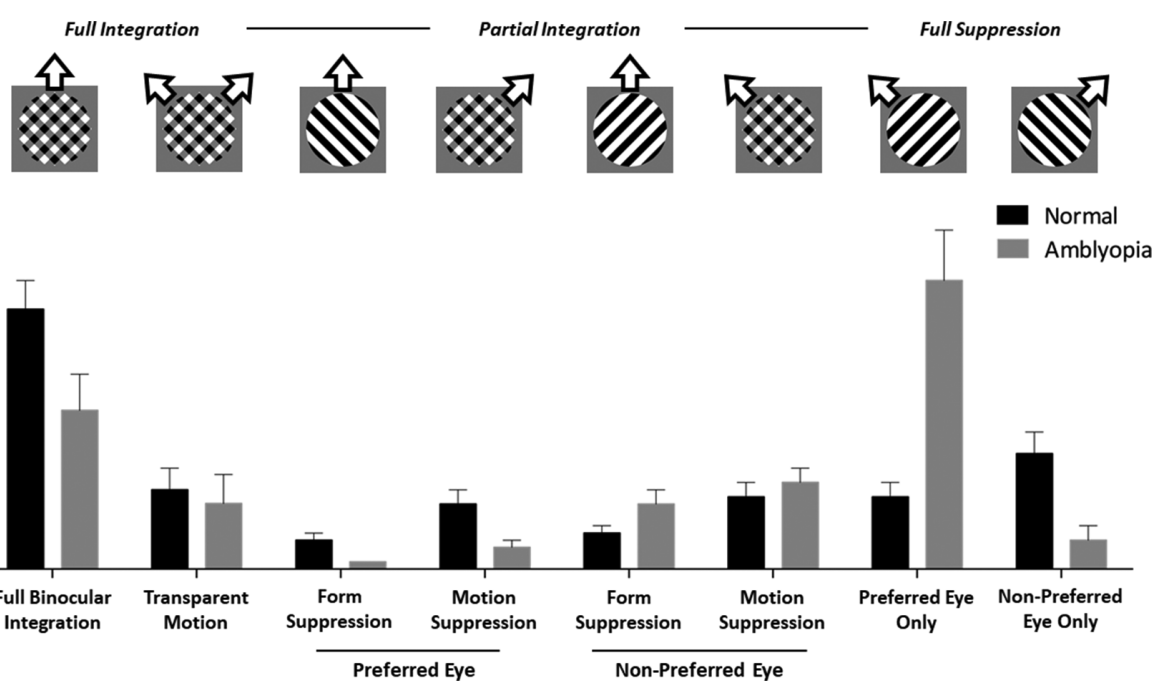

Figure 2. Proportion of time spent in each defined category of percept. Error bars denote standard error. 
Preferred Eye Form Dominance

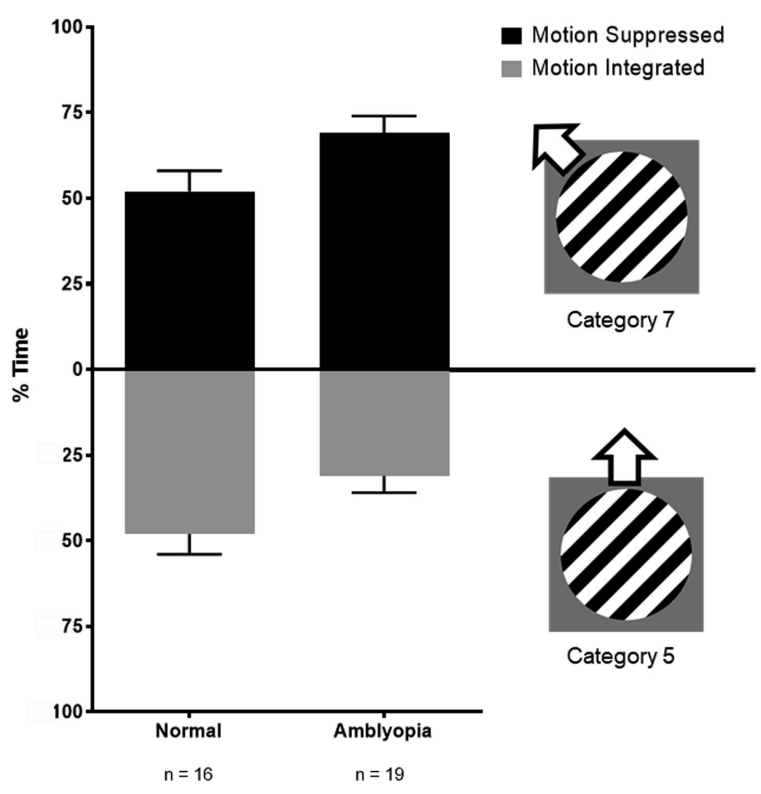

Figure 3. Extent to which binocular integration of motion information occurs during periods of nonpreferred eye suppression. Error bars denote standard error. Figure designed in style as per Andrews and Blakemore. ${ }^{87}$

Tukey's correction for multiple comparisons. A one-sample $t$-test was used to determine whether the mean percentage of motion integration during nonpreferred eye suppression in the amblyopia group differed from zero. Pearson's $R$ correlation coefficients were used to investigate the association between interocular acuity difference and nonpreferred eye suppression during rivalry in the amblyopia group, as well as the extent of motion integration during form suppression of the nonpreferred eye. To assess whether adaptation to the stimuli over the course of the experiment influenced integration responses, we analyzed the proportion of pattern motion responses (categories 1, 3, and 5) in the first three and last three trials of the experiment using a 2 (group: normal and amblyopia) $\times 2$ (order: first and last) $\times 3$ (trials: 1,2 , and 3) repeated measures ANOVA.

\section{Results}

Responses for motion direction revealed three peaks around each of the expected motion directions. In participants with normal vision, peak medians \pm SD were located at 46 degrees \pm 10.8 degrees, 90 degrees \pm 6.0 degrees, and 130 degrees \pm 9.9 degrees. For participants with amblyopia, peak medians \pm SD were located at 51 degrees \pm 9.6 degrees, 91 degrees \pm 7.6 degrees, and 132 degrees \pm 7.9 degrees.

Figure 2 illustrates the proportion of time spent in each percept category for participants with normal vision or amblyopia. As expected, individuals with amblyopia experienced longer periods of nonpreferred eye suppression (category 7; mean \pm SEM $40 \pm 7 \%$ of the time) than preferred eye suppression (category $8 ; 4 \pm 2 \%$; $\mathrm{t}_{19}=5.1, P<0.001$ ). In contrast, individuals with normal vision had similar periods of preferred eye suppression (category $8 ; 16 \pm 3 \%$ ) and nonpreferred eye suppression (category $7 ; 10 \pm 2 \% ; t_{38}=$ $1.2, P>0.05)$. The duration of nonpreferred eye suppres- sion during rivalry was positively correlated with the interocular acuity difference in the amblyopia group $(r=0.59, P$ $=0.008$; Fig. 4A), whereby the nonpreferred eye was more often suppressed at larger interocular acuity differences. Full binocular integration of form and motion information (category 1) occurred more frequently in the normal vision group $(36 \pm 4 \%)$ than in the amblyopia group (22 $\pm 5 \%$, $\left.t_{38}=2.14, P=0.039\right)$. Occurrence of simultaneous perception/transparent motion (category 2) was similar amongst the two groups (normal vision: $11 \pm 3 \%$; amblyopia: $9.1 \pm$ $\left.4 \% ; t_{38}=0.4, P>0.05\right)$. For periods of partial integration (categories 3 to 6; see Fig. 2, middle), a 2 (eye) $\times 2$ (suppression) $\times 2$ (group) repeated measures ANOVA found a significant interaction of eye $\times$ group $\left(F_{1,38}=23.39, P<0.001\right)$, as well as a main effect of suppression $\left(F_{1,38}=14.79, P<\right.$ $0.001)$. No interaction of eye $\times$ suppression $\times$ group was evident $\left(F_{1,38}=0.24, P>0.05\right)$. Motion information was more often suppressed than form information in individuals with normal vision $\left(t_{38}=4.46, P<0.001\right)$, regardless of whether the preferred eye (motion $9 \pm 2 \%$; form $4 \pm$ $1 \%$ ) or nonpreferred eye (motion $10 \pm 2$; form $5 \pm 1 \%$ ) was suppressed (form versus motion: $t_{38}=0.72, P>0.05$ ). However, in individuals with amblyopia, form and motion were similarly suppressed $\left(t_{38}=1.45, P>0.05\right)$, more so for the nonpreferred eye (motion $12 \pm 2 \%$ and form $9 \pm$ $2 \%$ ) than the preferred eye (motion $3 \pm 1 \%$; form $1 \pm 0.3 \%$; and form versus motion: $t_{38}=5.95, P<0.001$ ).

Periods where participants reported more than 2 minutes ( $5 \%$ of total viewing time) of nonpreferred eye form suppression (category 5; 16 normal vision and 19 amblyopia; see Fig. 3) were analyzed further. Binocular integration of motion information from the suppressed nonpreferred eye occurred $48.1 \pm 6.2 \%$ of the time in participants with normal vision and $31.2 \pm 5.8 \%$ of the time in participants with amblyopia $\left(t_{33}=-2.0, P=0.054\right.$; see Fig. 3$)$. A post hoc power calculation (using $G$ *Power version 3.1.9.7) with $d$ $=0.68$ found that observed power was 0.49 . Notably, the proportion of time that participants with amblyopia experienced binocular motion integration during suppression of the nonpreferred eye was significantly non-zero $\left(t_{18}=5.4, P\right.$ $=0.000004)$. The extent of motion integration during nonpreferred eye suppression was not correlated with interocular acuity difference ( $r=-0.43, P=0.07$; Fig. 4B).

We chose to exclude participants with less than 2 minutes of nonpreferred eye suppression because such a small sampling of time would skew the subsequent percentage calculation. Nevertheless, inclusion of these participants does not change our results. With all participant data included, motion integration occurred $56.5 \% \pm 6.4 \%$ (mean \pm SE) of the time in the control group and $29.7 \pm 5.7 \%$ of the time in the amblyopia group. Three out of the four excluded control participants had a motion integration rate of $>95 \%$ despite averaging 70 seconds of nonpreferred eye suppression. The remaining participant reported nonpreferred eye suppression of only 1 second. The only participant excluded from the amblyopia group reported a $1 \%$ motion integration rate from 58 seconds and $41 \%$ form integration rate from 82 seconds of nonpreferred eye suppression.

Adaptation is to be expected for any long-term stimulus presentation, and we used a repeated measures ANOVA to determine whether adaptation influenced motion responses. We found no effect of order $\left(F_{1,37}=0.26, P>0.05\right)$ or trials $\left(F_{2,74}=2.5, P>0.05\right)$ for the motion responses. There was a significant effect of group $\left(F_{1,37}=6.2, P=0.017\right)$, such that control participants reported $20.9 \pm 8 \%$ more pattern motion 
A

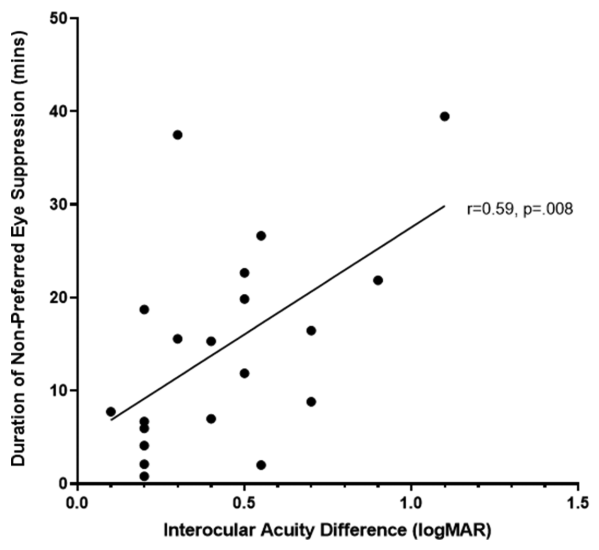

B

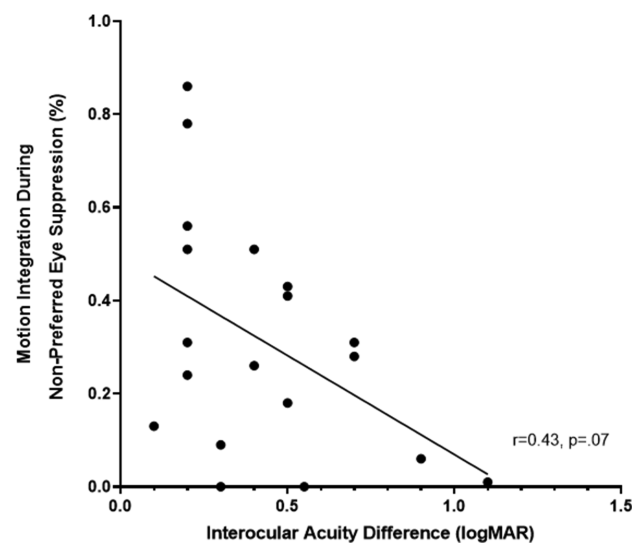

Figure 4. (A) Scatterplot demonstrating the relationship between interocular acuity difference (logMAR) and the duration (minutes) of nonpreferred eye suppression in the amblyopia group $(n=20)$. (B) Scatterplot showing the relationship between interocular acuity difference ( $\log$ MAR) and the extent of motion integration during nonpreferred eye suppression (percentage of time in category 5 versus category 7$)$ in the amblyopia group $(n=19)$. In all panels, different dots represent individual participants and the solid line represents the best linear fit.

than participants with amblyopia, consistent with our overall results. No interactions were significant $(P>0.05)$.

\section{Discussion}

Overall, our findings show that a lack of conscious awareness of visual information does not preclude its contribution to binocular processing in both normal vision and in amblyopia. Previously, binocular integration in amblyopia has only been demonstrated after alleviating interocular suppression by rebalancing the signal strength from each eye. ${ }^{21,22,31-34}$ Suppression of amblyopic eye information from conscious awareness was thought to preclude its contribution during binocular viewing. Our results show that despite strong suppression using high-contrast stimuli, ${ }^{23,24,33,91,92}$ visual information seen only by the suppressed amblyopic eye can be binocularly integrated and influence the overall visual percept. We further corroborate previous findings for the normal visual system that suppressed stimuli can be binocularly integrated. ${ }^{45,48,81,87,88}$ We also observed that periods of rivalry and simultaneous perception do occur for highcontrast dichoptic stimuli in observers with amblyopia.

Using perceptual states to infer underlying processing, our findings suggest that consciously suppressed visual information remains available for binocular processing even in amblyopia. This observation is consistent with recent neuroimaging data indicating that the neural signature of amblyopic eye suppression is not evident in early visual areas $\mathrm{V} 1, \mathrm{~V} 2$, and $\mathrm{V} 3,{ }^{93}$ thereby raising the possibility that suppressed information is available for downstream processing. Monocular viewing of plaids with the amblyopic eye is correlated with activity in the pulvinar and area V3 rather than $\mathrm{V} 5$ as is the case for non-amblyopic eye viewing and control eyes. ${ }^{80}$ This thalamo-cortical network may also support binocular integration of motion in the presence of interocular suppression. For example, although MT/V5 is thought to be critical for motion perception, lesions to this area only elevate motion thresholds and do not eliminate motion integration entirely. ${ }^{94-96}$ Further neuroimaging studies are required to explore these possibilities.

Although using a binocular rivalry paradigm enabled us to measure the extent of motion integration, we were not able to draw any conclusions regarding the extent of form integration. It is difficult to distinguish between form integration and superimposition of piecemeal percepts, which inevitably occurs during rivalry. We were not able to add additional response categories to differentiate mixed from piecemeal percepts due to the already complex nature of the psychophysical task and this is a limitation of our study. The strength of suppression also varies among individuals with amblyopia. We used stimuli with $100 \%$ contrast to encourage maximal suppression of the amblyopic eye, but individual variability in suppression exists. ${ }^{18}$ Other than the relative viewing dominance of each eye during binocular rivalry, we did not have an independent measure of suppression to determine each participant's suppression strength. In addition, we chose to fix the grating orientations presented to the preferred and nonpreferred eyes to simplify participant responses. The direction of motion was always balanced between the eyes as both eyes were presented with nasal to temporal motion. Using a range of different motion directions would have made it difficult to control for differences in plaid coherence that can occur between horizontal and vertical motion directions. ${ }^{55}$ However, our experimental design inevitably led to adaptation over the course of the experiment. Although we cannot rule out an effect of adaptation on our results, an analysis comparing pattern motion responses at the start and the end of the experiment did not reveal any adaptation effects.

In summary, our results demonstrate that visual information from a suppressed amblyopic eye remains available for visual processing. Our results have direct implications for the management of amblyopia in clinical practice. Adults with amblyopia are often not given proper refractive correction for their amblyopic eye because it is considered to be of no added benefit. ${ }^{97}$ There may be value in providing appropriate optical correction for the amblyopic eye in adults with amblyopia, not only for improving visual acuity, ${ }^{97}$ but also for enhancing the quality of visual information available for binocular integration. Our findings also support the theory underlying binocular approaches to amblyopia treatment, ${ }^{98,99}$ as suppressed information may remain available to intact binocular mechanisms in amblyopia. ${ }^{11,21,22,33,34,36,103,104,99-102}$ Since suppression 
renders a structurally binocular system functionally monocular, it remains a significant obstacle in the treatment of amblyopia. ${ }^{2,33,34,36,100}$ Although amblyopia is most successfully treated during childhood when cortical plasticity remains high, the visual system retains considerable plasticity even in adulthood. ${ }^{105-107}$ Efforts to identify and remove the factors that limit plasticity in adults have been promising, using methods such as perceptual learning, ${ }^{108}$ video games, ${ }^{109}$ dichoptic treatments, ${ }^{110}$ and noninvasive brain stimulation. ${ }^{111-113}$ Ongoing research into the nature of interocular suppression in amblyopia will enable refinement of these potential treatment approaches.

\section{Acknowledgments}

Supported by a NSERC PGS-D Grant (A.C.) and NSERC Grants RPIN-05394 and RGPAS-477166 (B.T.; Ottawa, ON, Canada)

Disclosure: A. Chow, None; A.E. Silva, None; K. Tsang, None; G. Ng, None; C. Ho, None; B. Thompson, None

\section{References}

1. Kiorpes L. Visual Processing in Amblyopia: Animal Studies. Strabismus. 2006;14(1):3-10.

2. Hamm LM, Black J, Dai S, Thompson B. Global processing in amblyopia: A review. Front Psychol. 2014;5(JUN):1-21.

3. Meier K, Giaschi DE. Unilateral amblyopia affects two eyes: Fellow eye deficits in amblyopia. Investig Ophthalmol Vis Sci. 2017;58(3):1779-1800.

4. Levi DM. Rethinking amblyopia 2020. Vision Res. 2020;176:118-129.

5. Hess RF, Thompson B, Baker DH. Binocular vision in amblyopia: Structure, suppression and plasticity. Ophthalmic Physiol Opt. 2014;34(2):146-162.

6. Birch EE. Amblyopia and binocular vision. Prog Retin Eye Res. 2013;33(1):67-84.

7. Jampolsky A. Characteristics of suppression in strabismus. AMA Arch Ophthalmol. 1955;54(5):683-696.

8. Travers T. Suppression of Vision in Squint and its Association with Retinal Correspondence and Amblyopia. Br J Ophthalmol. 1938;22(10):577-604.

9. Pratt-Johnson J, Wee H, Ellis S. Suppression associated with esotropia. Can J Ophthalmol. 1967;2(4):284-291.

10. Black JM, Thompson B, Maehara G, Hess RF. A compact clinical instrument for quantifying suppression. Optom Vis Sci. 2011;88(2):334-343.

11. Ding J, Sperling G. A gain-control theory of binocular combination. Proc Natl Acad Sci USA. 2006;103(4):11411146.

12. Babu RJ, Clavagnier SR, Bobier W, Thompson B, Hess RF. The regional extent of suppression: strabismics versus nonstrabismics. Invest Ophthalmol Vis Sci. 2013;54(10):6585-6593.

13. Babu RJ, Clavagnier S, Bobier WR, Thompson B, Hess RF. Regional Extent of Peripheral Suppression in Amblyopia. Investig Opthalmology Vis Sci. 2017;58(4):2329.

14. Maehara G, Thompson B, Mansouri B, Farivar R, Hess RF. The perceptual consequences of interocular suppression in amblyopia. Investig Ophthalmol Vis Sci. 2011;52(12):90119017.

15. Sireteanu R, Fronius M. Naso-temporal asymmetries in human amblyopia: Consequence of long-term interocular suppression. Vision Res. 1981;21(7):1055-1063.

16. Smith EL, Levi DM, Manny RE, Harwerth RS, White JM. The relationship between binocular rivalry and strabismic suppression. Investig Ophthalmol Vis Sci. 1985;26(1):8087.

17. Li JJ, Li JJ, Chen Z, et al. Spatial and Global Sensory Suppression Mapping Encompassing the Central $10^{\circ}$ Field in Anisometropic Amblyopia. Investig Opthalmology Vis Sci. 2017;58(1):481.

18. Li J, Thompson B, Lam CSYY, et al. The role of suppression in amblyopia. Invest Ophthalmol Vis Sci. 2011;52(7):41694176.

19. Hou C, Kim Y, Lai XJ, Verghese P. Degraded attentional modulation of cortical neural populations in strabismic amblyopia. J Vis. 2016;16(3):16.

20. Kwon M, Lu Z-L, Miller A, Kazlas M, Hunter DG, Bex PJ. Assessing Binocular Interaction in Amblyopia and Its Clinical Feasibility. Solomon SG, ed. PLoS One. 2014;9(6):e100156.

21. Mansouri B, Thompson B, Hess RF. Measurement of suprathreshold binocular interactions in amblyopia. Vision Res. 2008;48(28):2775-2784.

22. Huang C-B, Zhou J, Lu Z-L, Feng L, Zhou Y. Binocular combination in anisometropic amblyopia. $J$ Vis. 2009;9(3):17.1-17.16.

23. Spiegel DP, Baldwin AS, Hess RF. The Relationship Between Fusion, Suppression, and Diplopia in Normal and Amblyopic Vision. Invest Ophthalmol Vis Sci. 2016;57(13):5810-5817.

24. Kwon M, Wiecek E, Dakin SC, Bex PJ. Spatial-frequency dependent binocular imbalance in amblyopia. Sci Rep. 2015;5(1):1-12.

25. Pardhan S, Gilchrist J. Binocular contrast summation and inhibition in amblyopia. Doc Ophthalmol. 1992;82(3):239248.

26. Levi DM, Harwerth RS, Smith EL. Binocular interactions in normal and anomalous binocular vision. Doc Ophthalmol. 1980;49(2):303-324.

27. Lema SA, Blake R. Binocular summation in normal and stereoblind humans. Vision Res. 1977;17(6):691-695.

28. Pardhan S, Whitaker A. Binocular summation in the fovea and peripheral field of anisometropic amblyopes. Curr Eye Res. 2000;20(1):35-44.

29. Sengpiel F, Jirmann K-U, Vorobyov V, Eysel UT. Strabismic Suppression Is Mediated by Inhibitory Interactions in the Primary Visual Cortex. Cereb Cortex. 2006;16(12):17501758.

30. Webber AL, Schmid KL, Baldwin AS, Hess RF. Suppression rather than visual acuity loss limits stereoacuity in amblyopia. Investig Ophthalmol Vis Sci. 2020;61(6):50.

31. Hallum LE, Shooner C, Kumbhani RD, et al. Altered Balance of Receptive Field Excitation and Suppression in Visual Cortex of Amblyopic Macaque Monkeys. J Neurosci. 2017;37(34):8216-8226.

32. Ding J, Levi DM. Rebalancing binocular vision in amblyopia. Ophthalmic Physiol Opt. 2014;34(2):199-213.

33. Ding J, Klein SA, Levi DM. Binocular combination in abnormal binocular vision. J Vis. 2013;13(2):14.

34. Huang C-B, Zhou J, Lu Z-L, Zhou Y. Deficient binocular combination reveals mechanisms of anisometropic amblyopia: signal attenuation and interocular inhibition. $J$ Vis. 2011;11(6):1-17.

35. Huang PC, Baker DH, Hess RF. Interocular suppression in normal and amblyopic vision: Spatio-temporal properties. J Vis. 2012;12(11):29-29.

36. Baker DH, Meese TS, Mansouri B, Hess RF. Binocular summation of contrast remains intact in strabismic amblyopia. Investig Ophthalmol Vis Sci. 2007;48(11):5332-5338.

37. Baker DH, Meese TS, Hess RF. Contrast masking in strabismic amblyopia: Attenuation, noise, interocular suppression and binocular summation. Vis Res. 2008;48(15):1625-1640. 
38. Blake R. A Neural Theory of Binocular Rivalry. Psychol Rev. 1989;96(1):145-167.

39. Blake R, Fox R. Binocular rivalry suppression: Insensitive to spatial frequency and orientation change. Vis Res. 1974;14(8):687-692.

40. Wales R, Fox R. Increment detection thresholds during binocular rivalry suppression. Percept Psychophys. 1970;8(2):90-94.

41. Fox R, Check R. Independence between binocular rivalry suppression duration and magnitude of suppression. J Exp Psychol. 1972;93(2):283-289.

42. Blake R, Camisa J. On the inhibitory nature of binocular rivalry suppression. J Exp Psychol Hum Percept Perform. 1979;5(2):315-323.

43. Nguyen VA, Freeman AW, Alais D. Increasing depth of binocular rivalry suppression along two visual pathways. Vision Res. 2003;43(19):2003-2008.

44. Pearson J, Clifford CWG. Suppressed patterns alter vision during binocular rivalry. Curr Biol. 2005;15(23):21422148.

45. Wiesenfelder H, Blake R. Apparent motion can survive binocular rivalry suppression. Vis Res. 1991;31(9):15891599.

46. O'Shea RP, Crassini B. Interocular transfer of the motion after-effect is not reduced by binocular rivalry. Vision Res. 1981;21(6):801-804.

47. Lehmkuhle SW, Fox R. Effect of binocular rivalry suppression on the motion aftereffect. Vision Res. 1975;15(7):855859.

48. Wiesenfelder H, Blake R. The neural site of binocular rivalry relative to the analysis of motion in the human visual system. $J$ Neurosci. 1990;10(12):3880-3888.

49. Blake R, Westendorf DH, Overton R. What is suppressed during binocular rivalry? Perception. 1980;9:223-231.

50. Fang $\mathrm{F}$, He S. Cortical responses to invisible objects in the human dorsal and ventral pathways. Nat Neurosci. 2005;8(10):1380-1385.

51. Sterzer P, Haynes JD, Rees G. Fine-scale activity patterns in high-level visual areas encode the category of invisible objects. J Vis. 2008;8(15):1-12.

52. Sterzer P, Jalkanen L, Rees G. Electromagnetic responses to invisible face stimuli during binocular suppression. Neuroimage. 2009;46(3):803-808.

53. Adelson EH, Movshon JA. Phenomenal coherence of moving visual patterns. Nature. 1982;300(5892):523-525.

54. Hupé J-M, Rubin N. The dynamics of bi-stable alternation in ambiguous motion displays: a fresh look at plaids. Vision Res. 2003;43(5):531-548.

55. Hupé J-M, Rubin N. The oblique plaid effect. Vision Res. 2004;44(5):489-500.

56. Thompson B, Aaen-Stockdale CR, Mansouri B, Hess RF. Plaid perception is only subtly impaired in strabismic amblyopia. Vis Res. 2008;48(11):1307-1314.

57. Born RT, Bradley DC. Structure and function of visual area MT. Annu Rev Neurosci. 2005;28:157-189.

58. Majaj NJ, Carandini M, Movshon JA. Motion integration by neurons in macaque MT is local, not global. J Neurosci. 2007;27(2):366-370.

59. Albright TD. Direction and orientation selectivity of neurons in visual area MT of the macaque. J Neurophysiol. 1984;52(6):1106-1130.

60. Movshon J, Adelson E, Gizzi M, Newsome WT. The analysis of moving visual patterns. In: Chagas C, Gattass R, Gross $\mathrm{C}$, eds. Pattern Recognition Mechanisms. Vatican City, Rome: Pontificiae Academiae Scientiarium Scripta Varia; 1985:117-151.

61. Heeger DJ. Model for the extraction of image flow. $J$ Opt Soc Am A. 1987;4(8):1455-1471.
62. Simoncelli EP, Heeger DJ. A model of neuronal responses in visual area MT. Vision Res. 1998;38(5):743-761.

63. Pack CC, Born RT. Temporal dynamics of a neural solution to the aperture problem in visual area MT of macaque brain. Nature. 2001;409(6823):1040-1042.

64. Rodman HR, Albright TD. Single-unit analysis of patternmotion selective properties in the middle temporal visual area (MT). Exp brain Res. 1989;75(1):53-64.

65. Stoner GR, Albright TD. Neural correlates of perceptual motion coherence. Nature. 1992;358(6385):412414.

66. Rust NC, Mante V, Simoncelli EP, Movshon JA. How MT cells analyze the motion of visual patterns. Nat Neurosci. 2006;9(11):1421-1431.

67. Movshon JA, Newsome WT. Visual response properties of striate cortical neurons projecting to area MT in macaque monkeys. J Neurosci. 1996;16(23):7733-7741.

68. Perrone JA. A visual motion sensor based on the properties of V1 and MT neurons. Vision Res. 2004;44(15):17331755.

69. Smith MA, Majaj NJ, Movshon JA. Dynamics of motion signaling by neurons in macaque area MT. Nat Neurosci. 2005;8(2):220-228.

70. Tinsley CJ, Webb BS, Barraclough NE, Vincent CJ, Parker A, Derrington AM. The nature of V1 neural responses to 2D moving patterns depends on receptive-field structure in the marmoset monkey. J Neurophysiol. 2003;90(2):930937.

71. Guo K, Benson PJ, Blakemore C. Pattern motion is present in V1 of awake but not anaesthetized monkeys. Eur J Neurosci. 2004;19(4):1055-1066.

72. Mikami A, Newsome WT, Wurtz RH. Motion selectivity in macaque visual cortex. II. Spatiotemporal range of directional interactions in MT and V1. J Neurophysiol. 1986;55(6):1328-1339.

73. Churchland MM, Priebe NJ, Lisberger SG. Comparison of the spatial limits on direction selectivity in visual areas MT and V1.J Neurophysiol. 2005;93(3):1235-1245.

74. Mingolla E, Todd JT, Norman JF. The perception of globally coherent motion. Vis Res. 1992;32(6):1015-1031.

75. Wilson HR, Ferrera VP, Yo C. A psychophysically motivated model for two-dimensional motion perception. Vis Neurosci. 1992;9(1):79-97.

76. Rubin N, Hochstein S. Isolating the effect of onedimensional motion signals on the perceived direction of moving two-dimensional objects. Vision Res. 1993;33(10):1385-1396.

77. Barth E, Watson A. A geometric framework for nonlinear visual coding. Opt Express. 2000;7(4):155-165.

78. Thompson B, Aaen-Stockdale C, Koski L, Hess RF. A double dissociation between striate and extrastriate visual cortex for pattern motion perception revealed using rTMS. Hum Brain Mapp. 2009;30(10):3115-3126.

79. Tang Y, Chen L, Liu Z, Liu C, Zhou Y. Low-level processing deficits underlying poor contrast sensitivity for moving plaids in anisometropic amblyopia. Vis Neurosci. 2012;29(6):315-323.

80. Thompson B, Villeneuve MY, Casanova C, Hess RF. Abnormal cortical processing of pattern motion in amblyopia: Evidence from fMRI. Neuroimage. 2012;60(2):1307-1315.

81. Cobo-Lewis AB, Gilroy LA, Smallwood TB. Dichoptic plaids may rival, but their motions can integrate. Spat Vis. 2000;13(4):415-429.

82. Smith AT. Coherence of plaids comprising components of disparate spatial frequencies. Vision Res. 1992;32(2):393397.

83. Delicato LS, Derrington AM. Coherent motion perception fails at low contrast. Vision Res. 2005;45(17):2310-2320. 
84. Stone LS, Watson AB, Mulligan JB. Effect of contrast on the perceived direction of a moving plaid. Vis Res. 1990;30(7):1049-1067.

85. Thompson P. Perceived rate of movement depends on contrast. Vision Res. 1982;22(3):377-380.

86. Kim J, Wilson HR. Dependence of plaid motion coherence on component grating directions. Vision Res. 1993;33(17):2479-2489.

87. Andrews TJ, Blakemore C. Form and motion have independent access to consciousness. Nat Neurosci. 1999;2(5):405406.

88. Carney T, Shadlen M, Switkes E. Parallel processing of motion and colour information. Nature. 1987;328(6131):647-649.

89. Andrews TJ, Blakemore C. Integration of motion information during binocular rivalry. Vision Res. 2002;42(3):301309.

90. Tailby C, Majaj NJ, Movshon JA. Binocular integration of pattern motion signals by MT neurons and by human observers. J Neurosci. 2010;30(21):7344-7349.

91. Reynaud A, Hess RF. Is Suppression Just Normal Dichoptic Masking? Suprathreshold Considerations. Investig Opthalmology Vis Sci. 2016;57(13):5107.

92. Mao Y, Min SH, Chen S, et al. Binocular Imbalance in Amblyopia Depends on Spatial Frequency in Binocular Combination. Investig Opthalmology Vis Sci. 2020;61(8):7.

93. Thompson B, Maehara G, Goddard E, Farivar R, Mansouri B, Hess R. Long-Range Interocular Suppression in Adults with Strabismic Amblyopia: A Pilot fMRI Study. Vision. 2019;3(1):2.

94. Baker CL, Hess RF, Zihl J. Residual motion perception in a \&quot;motion-blind\&quot; patient, assessed with limitedlifetime random dot stimuli. J Neurosci. 1991;11(2):454461.

95. Rizzo M, Nawrot M, Zihl J. Motion and shape perception in cerebral akinetopsia. Brain. 1995;118 (Pt 5):1105-1127.

96. Rudolph K, Pasternak T. Transient and permanent deficits in motion perception after lesions of cortical areas MT and MST in the macaque monkey. Cereb Cortex. 1999;9(1):90100.

97. Gao TY, Anstice N, Babu RJ, et al. Optical treatment of amblyopia in older children and adults is essential prior to enrolment in a clinical trial. Ophthalmic Physiol Opt. 2018;38(2):129-143.

98. Hess RF, Mansouri B, Thompson B. A new binocular approach to the treatment of amblyopia in adults well beyond the critical period of visual development. Restor Neurol Neurosci. 2010;28(6):793-802.

99. Barrett BT, Panesar GK, Scally AJ, Pacey IE. Binocular summation and other forms of non-dominant eye contribution in individuals with strabismic amblyopia during habitual viewing. PLoS One. 2013;8(10):e77871.
100. Baker DH, Lygo FA, Meese TS, Georgeson MA. Binocular summation revisited: Beyond $\sqrt{ } 2$. Psychol Bull. 2018;144(11):1186-1199.

101. Pardhan S, Gilchrist J. Binocular contrast summation and inhibition in amblyopia. The influence of the interocular difference on binocular contrast sensitivity. Doc Ophthalmol. 1992;82(3):239-248.

102. Dorr M, Kwon M, Lesmes LA, et al. Binocular Summation and Suppression of Contrast Sensitivity in Strabismus, Fusion and Amblyopia. Front Hum Neurosci. 2019; 13:234.

103. Dougherty K, Cox MA, Westerberg JA, Maier A. Binocular Modulation of Monocular V1 Neurons. Curr Biol. 2019;29(3):381-391.e4.

104. Vedamurthy I, Suttle CM, Alexander J, Asper LJ. A psychophysical study of human binocular interactions in normal and amblyopic visual systems. Vis Res. 2008;48(14):1522-1531.

105. Bavelier D, Levi DM, Li RW, Dan Y, Hensch TK. Removing brakes on adult brain plasticity: from molecular to behavioural interventions. J Neurosci. 2010;30(45):1496414971.

106. Hensch TK, Quinlan EM. Critical periods in amblyopia. Vis Neurosci. 2018;35(2018):E014.

107. Eckmann S, Klimmasch L, Shi BE, Triesch J. Active efficient coding explains the development of binocular vision and its failure in amblyopia. Proc Natl Acad Sci. 2020;117(11):6156-6162.

108. Levi DM, Li RW. Perceptual learning as a potential treatment for amblyopia: A mini-review. Vision Res. 2009;49(21):2535-2549.

109. Bavelier D, Shawn Green C, Pouget A, Schrater P. Brain plasticity through the life span: Learning to learn and action video games. Annu Rev Neurosci. 2012;35:391416.

110. Brin TA, Chow A, Carter C, Oremus M, Bobier W, Thompson B. Efficacy of vision-based treatments for children and teens with amblyopia: a systematic review and meta-analysis of randomised controlled trials. BMJ Open Ophthalmol. 2021;6(1):e000657.

111. Thompson B, Mansouri B, Koski L, Hess RF. Brain Plasticity in the Adult: Modulation of Function in Amblyopia with rTMS. Curr Biol. 2008;18(14):1067-1071.

112. Spiegel DP, Byblow WD, Hess RF, Thompson B. Anodal transcranial direct current stimulation transiently improves contrast sensitivity and normalizes visual cortex activation in individuals with amblyopia. Neurorehabil Neural Repair. 2013;27(8):760-769.

113. Spiegel DP, Li J, Hess RF, et al. Transcranial direct current stimulation enhances recovery of stereopsis in adults with amblyopia. Neurotherapeutics. 2013;10(4):831839. 